\title{
Role of Deficits in Pathogen Recognition Receptors in Infection Susceptibility
}

\author{
Cristina Cunha, Samuel M. Gonçalves, \\ and Agostinho Carvalho
}

\section{Introduction: A Genetic Perspective of the Host-Pathogen Interaction}

The determinism of human infectious diseases is still vastly misconstrued. Because exposure to a pathogen is requisite for infection and disease to occur, infectious diseases are often regarded as textbook examples of purely environmental diseases. However, a characteristic feature of many human infectious diseases is the interindividual variability in the development and progression of clinical disease. While a significant contribution might be credited to virulence traits of the infectious agent, recent evidence has highlighted the dominant role of heritable factors in defining susceptibility to infection [1-6]. Twin studies have played a significant part in unraveling host genetic factors involved in susceptibility to infectious diseases, although the relative contribution of heredity and environment to infection in twins remains disputed [7]. Nonetheless, a groundbreaking study from the late 1980s reported that adopted children had a prominently increased risk of death from infectious diseases if at least one of their biological parents had died prema-

C. Cunha · S. M. Gonçalves · A. Carvalho $(\bowtie)$ Life and Health Sciences Research Institute (ICVS), School of Medicine, University of Minho, Braga, Portugal

ICVS/3B's - PT Government Associate Laboratory, Braga/Guimarães, Portugal e-mail: agostinhocarvalho@med.uminho.pt turely from the same infection [8]. Mouse studies have also widely illustrated the importance of host genetic-driven effects, by showing disparities between inbred strains concerning pathogen loads, cytokine responses, and outcomes following infection [9]. Thus, there is considerable evidence supporting the contribution of host genetics to infectious disease; a well-known example is the protective role of the sickle cell trait against the severe forms of malaria caused by Plasmodium falciparum [10].

Our current understanding of the genetic susceptibility to human infectious diseases is derived from the study of individuals with rare monogenic defects underlying susceptibility to a narrow range of pathogens and from population-based studies to identify common polymorphisms associated with disease. Such landmark discoveries have established that predisposition to infection segregates in either a Mendelian (monogenic) or a polygenic pattern of inheritance. By implicating these genetic variants in the immune response to selected pathogens, these reports have provided crucial insights into the genetic control of antimicrobial host defenses in humans. Extension of these genetic approaches to the dissection of the associated molecular and cellular mechanisms may further unravel the genetic architecture of susceptibility to infectious diseases and support future studies evaluating host-pathogen genetic interactions and potentially driving clinical translation. In particular, the analysis of the 
transcriptional landscape of the host-pathogen interaction under conditions of specific immune deficiency may contribute to the disclosure of the permissive conditions underlying the emergence of different infectious diseases. In this chapter, we focus on genetic variation in pattern recognition receptors (PRRs) and its role in susceptibility to infectious diseases in patients with primary and acquired immunodeficiencies. Also discussed is the impact of genetic variation in these receptors on the activation of antimicrobial immune responses and how these processes can be exploited in personalized medical interventions based on individual host genetic profiles.

\section{Genetic Principles and Approaches for Identifying Susceptibility Genes}

Perhaps the most compelling evidence that host genetics indeed determines the development of infectious disease arises from primary immunodeficiencies, first described in the late 1940s and early 1950s [1]. Primary immunodeficiencies usually present with infections due to common or opportunistic pathogens, resulting from a clearcut deficit in a single gene. Such immune dysfunction is usually limited to a very small number of individuals or families, but the identification of the underlying genetic defects is very informative on immune defense mechanisms. On the other hand, susceptibility to infections in the general population can be influenced by polymorphisms across multiple genes, with the specific contribution to the phenotype being typically more difficult to establish.

The current interest in the role of rare, largeeffect variants as predisposing factors to infectious diseases has prompted the description of an increasing number of single-gene defects underlying phenotypes associated with a certain pathogen selectivity. The identification of mutations in individual immune-related genes influencing susceptibility to a narrow range of different pathogens has led to the evolving concept of pathogen-selective immunodeficiency [11]. It should be stressed that although these immunodeficiency states are widely considered to be discriminating, the specificity of pathogen susceptibility is not always absolute. Nevertheless, the range of pathogen diversity is typically much narrower in humans than that observed in the corresponding mouse knockout models. One difference is that human studies involve naturally acquired infection while mouse models generally involve administration of pathogens, often at high inocula to induce disease.

Early studies of genetic susceptibility to infectious diseases resorted to genome-wide linkage analyses and candidate gene approaches and identified only a restricted number of strongly associated loci that have been independently validated. Linkage approaches have been employed successfully in the study of monogenic diseases and were successively applied in attempts to define the susceptibility loci underlying common diseases. The most commonly used design involved the study of affected sibling pairs and had some degree of success in identifying loci linked to some infectious diseases, in particular leprosy [12]. However, a major drawback of linkage analyses lies in the difficulty in recruiting numerous multicase families in which two siblings are affected and by the lack of adequate study power [3].

Candidate gene studies comprise the genotyping of common polymorphisms in biologically plausible genes and pathways, typically in unrelated case and control individuals. The degree of replication between candidate gene studies is often poor, most likely due to small sample sizes limiting the study power, unrecognized population stratification, failure to correct for multiple testing during statistical analysis, and missing or inaccurate clinical information. Additional causes for lack of replication may include differences across studies in the phenotypic definition of cases (e.g., a significant bias might be introduced by the use of different diagnostic procedures) and controls, unidentified variation in gene-environment interactions, and actual genetic heterogeneity between populations [13]. The candidate gene approach is further hampered by its reliance on existing and possibly inaccurate biological hypotheses to select genes for study. Despite these limitations, candidate gene studies 
have disclosed a number of robust, independently replicated associations with infectious diseases.

\section{Pattern Recognition Receptors and Innate Immunity}

In 1992, Charles Janeway, Jr., advanced the field of innate immunity toward new horizons with his concept of selective recognition of conserved microbial structures by germline-encoded PRRs [14]. Indeed, it is nowadays well established that the first step in the development of an innate immune response implicates pathogen recognition by PRRs in an acute and conserved fashion [15]. Although there are substantial differences in the ways in which the multiple innate cell populations recognize specific pathogens, the overall framework is similar and involves the binding of conserved pathogenassociated molecular patterns (PAMPs) such as microbial cell wall constituents, nucleic acids, or metabolic products by PRRs. There are five major classes of receptors: Toll-like receptors (TLRs), C-type lectin receptors (CLRs), nucleotide-binding oligomerization domain (NOD) leucine-rich repeat containing receptors (NLRs), retinoic acid-inducible gene I protein (RIG-I) helicase receptors, and absent in melanoma 2 (AIM2)-like receptors (ALRs) [6]. Generally, by inducing the secretion of proinflammatory cytokines and chemokines, PRRs not only mediate downstream intracellular events related to pathogen clearance but also participate in complex and disparate processes of immunomodulation and activation of adaptive immunity through the coordination of $\mathrm{T}$ cell and $B$ cell responses [16]. Pathogen recognition by the innate immune system is further supported by the opsonic activity of soluble PRRs, including collectins, ficolins, pentraxins, and complement components, which facilitate the interaction with phagocytes. On the other hand, PRRs are also able to respond to products released from damaged host cells during infection and other causes of injury (e.g., trauma and ischemia reperfusion), including nucleic acids and alarmin proteins, collectively known as danger-associated molecular patterns.
The role of TLRs in antimicrobial defense was first proposed in 1996 by Lemaitre and colleagues, following the observation that fruit flies lacking the hematocyte receptor Toll - which indirectly recognizes pathogens through the cytokine-like protein Spätzle - were highly susceptible to infection with fungi and Gram-negative bacteria [17]. This study was followed shortly by the discovery of TLRs expressed on cells of the mammalian immune system, and since then, 13 TLRs have been discovered. The extracellular domains of these receptors contain leucine-rich repeats that recognize PAMPs from all major classes of pathogens, whereas the amino acid sequence of the cytoplasmic domain is highly homologous to the sequences in the interleukin (IL)-1 and IL-18 receptors [18]. Ligand recognition by TLRs and intracellular signaling transduction by adaptor molecules that contain Toll-IL-1R (TIR) domains activate kinase cascades and promote the translocation of transcription factors to the nucleus, where they induce gene expression and downstream production of cytokines [15, 19] (Fig. 6.1).

The large family of CLRs includes members such as dectin-1, dectin-2, macrophage mannose receptor, dendritic cell-specific intercellular adhesion molecule 3-grabbing non-integrin (DC-SIGN), macrophage inducible C-type lectin (Mincle), macrophage C-type lectin (MCL), and dectin-2. These receptors have carbohydrate recognition domains and bind microbial polysaccharides commonly present in fungi and bacteria [20]. Dectin-1 was the first CLR to be identified and is currently the best described nonTLR receptor able to instruct activation of adaptive immunity. Following recognition of $\beta$-1,3-glucans, dectin-1 triggers different intracellular signaling pathways that, synergistically and through cross-regulatory mechanisms, regulate and fine-tune nuclear factor (NF)- $\kappa B$ activation and cytokine gene expression [21] (Fig. 6.2).

In addition to the mainly membrane-bound TLRs and CLRs, there are cytoplasmic receptors - NLRs and the DNA-sensing RIG-I helicase receptors - that are activated by pathogens when they invade a cell. NLRs recognize the peptidoglycans of the bacterial cell 


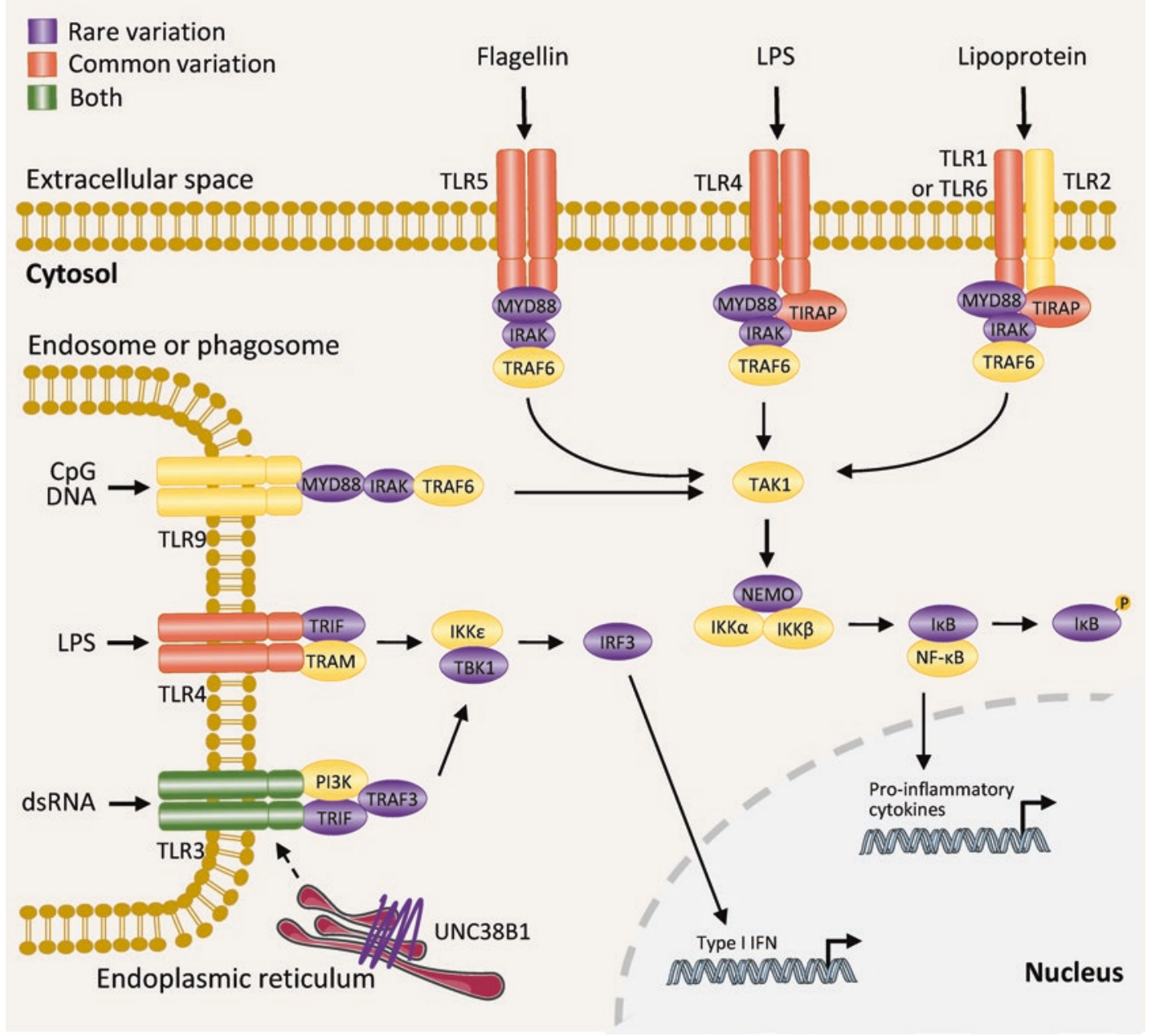

Fig. 6.1 Genetic defects affecting Toll-like receptor signaling and their role in susceptibility to infection. Tolllike receptors (TLRs) are present on the cell surface and in endosomes, where they detect pathogen-associated molecular patterns (PAMPs) such as lipopolysaccharide (LPS), lipoprotein, flagellin, CpG DNA, and doublestranded RNA. Upon stimulation, TLRs activate two disparate pathways that involve myeloid differentiation primary response 88 (MyD88) and/or Toll-interleukin (IL)-1 receptor (TIR) domain-containing adapter-inducing interferon (IFN)- $\beta$ (TRIF). Crosstalk between TLR signaling cascades underlies the activation of different cellular processes, including the transcription of proinflammatory cytokines and chemokines and type I

wall and can activate inflammasomes, multimeric protein complexes that convert inactive pro-IL-1 $\beta$ and pro-IL-18 into bioactive cytokines [22]. The NLR family members NOD-containing receptors 1 (NOD1) and NOD2 recognize muramyl peptide
IFN. Major genetic variation in TLR signaling pathways implicated in susceptibility to infection is indicated in purple (rare), red (common), or green (evidence of both rare and common variation). TIRAP Toll-interleukin-1 receptor (TIR) domain-containing adaptor protein, TRAM TRIF-related adaptor molecule, IRAK IL-1 receptorassociated kinase, TRAF tumor necrosis factor receptorassociated factor, UNC93B1 unc-93 homologue B1, TAK1 transforming growth factor- $\beta$-activated kinase $1, N F-\kappa B$ nuclear factor- $\mathrm{\kappa B}, N E M O \mathrm{NF}-\mathrm{\kappa B}$ essential modulator, $I K K$ inhibitor of NF- $\kappa \mathrm{B}$ kinase, $I \kappa B$ inhibitor of $\mathrm{NF}-\kappa \mathrm{B}$, $I R F$ IFN regulatory factor, TBK1 TANK-binding kinase 1 , $P I 3 K$ phosphoinositide 3-kinase, $d s R N A$ double-stranded RNA

moieties of the peptidoglycans of Gram-negative and Gram-positive bacteria, respectively [23, 24]. The RIG-I helicase receptors are known to recognize mainly viral nucleic acids and to activate inflammasome formation [25]. 


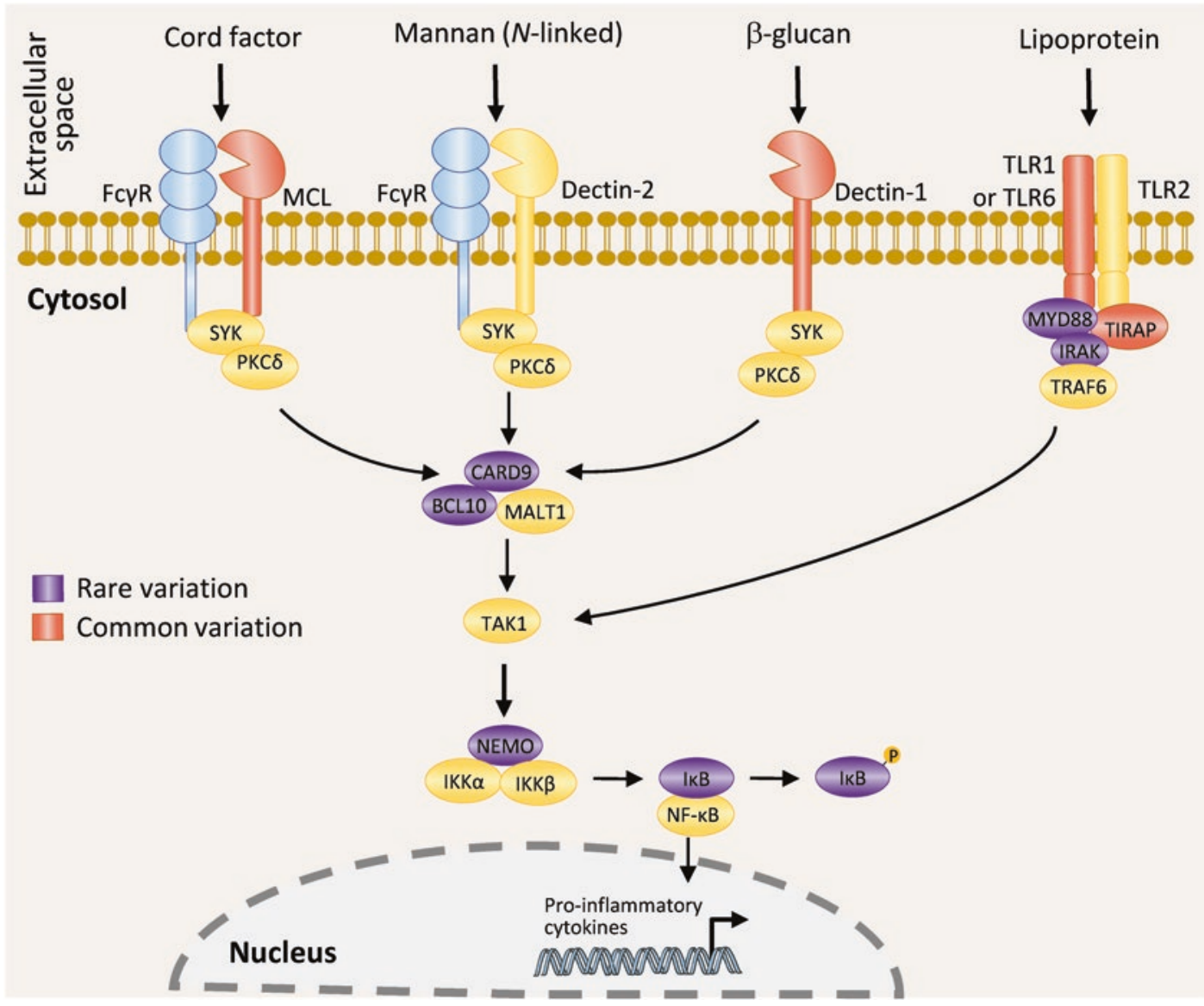

Fig. 6.2 Genetic defects affecting C-type lectin receptor signaling and their role in susceptibility to infection. The family of C-type lectin receptors (CLRs) recognizes microbial polysaccharides commonly present in fungi and bacteria. Cord factor is a commonly used term to refer to trehalose dimycolate, a glycolipid molecule found in the cell wall of $M$. tuberculosis and similar species. Upon stimulation, CLRs activate intracellular signaling pathways that, synergistically and through crossregulatory mechanisms, regulate and fine-tune nuclear factor (NF)- $\mathrm{kB}$ activation and cytokine gene expression. Major genetic variation in CLR signaling pathways implicated in susceptibility to infection is indicated in

Ultimately, the coordinated regulation of the immune response will depend not only on the relative degree of stimulation of the individual receptors but also on the level of receptor cooperation and cellular localization. For purple (rare) or red (common). $F C \gamma R \mathrm{Fc} \gamma$ receptor, $M C L$ macrophage C-type lectin, $S Y K$ spleen tyrosine kinase, $P K C \delta$ protein kinase $\mathrm{C}-\delta, M y D 88$ myeloid differentiation primary response 88, TIRAP Toll-interleukin-1 receptor (TIR) domain-containing adaptor protein, IRAK IL-1 receptor-associated kinase, TRAF tumor necrosis factor receptor-associated factor, $C A R D 9$ caspase recruitment domain-containing protein 9, BCL1O B cell CLL/ lymphoma 10, MALT1 mucosa-associated lymphoid tissue lymphoma translocation protein $1, N F-\kappa B$ nuclear

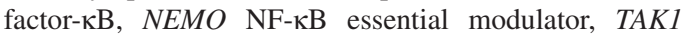
transforming growth factor- $\beta$-activated kinase $1, I K K$ inhibitor of NF-кB kinase

example, synergy between TLRs and NOD2 is crucial for the activation of host defense against mycobacteria and staphylococci [26], and crosstalk between TLRs and CLRs is needed for optimal antifungal responses [27]. 


\section{Genetic Defects in Pattern Recognition Receptors and Susceptibility to Infection}

Genetic variants in the genes encoding PRRs can affect susceptibility to many infectious diseases. Importantly, genetic defects in these receptors or the downstream signaling pathways can cause immunodeficiency phenotypes rendering patients extremely susceptible to severe, life-threatening infections. We know of genetic defects across the different classes of PRRs, although in some cases (e.g., the NLR family) these have yet to be linked with susceptibility to infection. An overview of the genetic variants affecting PRRs reported in association with susceptibility to specific infectious diseases is presented in Table 6.1.

\section{Genetic Variation in Toll-Like Receptor Signaling}

Soon after the initial description of TLRs, genetic variability in these molecules was proposed to underlie differences in susceptibility to infectious and inflammatory diseases [28]. The first genetic variation to be described was polymorphisms in TLR4, specifically two amino acid changes reported to decrease the interaction of the receptor with lipopolysaccharide [29] and to increase susceptibility to Gram-negative bacterial sepsis [30]. During the subsequent decade and up until now, a multitude of studies described genetic variation in practically all TLRs (Fig. 6.1).

Myeloid differentiation primary response 88 (MyD88) is an adaptor molecule that transduces signals from TLRs (with the exception of TLR3 and the IL-1 and IL-18 receptors) [31]. The signaling involves a cascade of protein kinases which include the serine-threonine IL-1Rassociated kinase 4 (IRAK4) [19]. The activation of the MyD88 and IRAK4 pathways has been deemed essential for the immune response to pyogenic bacteria based on the study of patients with rare mutations in these genes that resulted in invasive disease by Streptococcus pneumoniae and, to a lesser extent, by Staphylococcus aureus, Pseudomonas aeruginosa, or Salmonella species
$[32,33]$. Several hypomorphic mutations have been identified in MYD 88 and IRAK4 genes; two of them leading to MyD88 deficiency affecting amino acids in key positions for the interaction of the adaptor with IRAK4 [34]. Despite the manifest susceptibility to pyogenic bacteria, children with MyD88 and IRAK4 deficiency are typically resistant to other bacteria, mycobacteria, viruses, and fungi, and classically, their immunodeficiency improves with age, with less frequent and less severe forms of infection [35]. This may suggest that the development of protective T cell- or B cell-mediated immune responses after infancy compensates for the defective inflammatory reaction in the absence of proper TLR signaling [36].

Mutations in genes from the NF- $\mathrm{BB}$ pathway that interrupt multiple innate and adaptive pathways that signal to NF- $\kappa \mathrm{B}$, including TLRmediated signaling, have also been identified [37-40]. In particular, hypomorphic mutations in NF- $\kappa \mathrm{B}$ essential modulator $(N E M O)$, which encodes the I- $\mathrm{\kappa B}$ kinase regulatory subunit IKK $\gamma$, and $\mathrm{I} \kappa \mathrm{B} \alpha$ inhibitor of NF- $\kappa \mathrm{B}$ (IKBA) have been reported to underlie typically severe infections by a broad range of pathogens, including encapsulated bacteria, atypical mycobacteria, fungi, and viruses, and are also associated with ectodermal dysplasia [37-40].

In addition to the RIG-I helicase receptors, TLR3, TLR7, TLR8, and TLR9 bind to different microbial nucleic acids $[15,19]$. Genetic defects in TLR3 [41] or proteins involved in the TLR3 pathway such as unc-93 homologue B1 (UNC93B1) [42] and TIR-domain-containing adapter-inducing interferon (IFN)- $\beta$ (TRIF) [43] or tumor necrosis factor (TNF) receptorassociated factor 3 (TRAF3) [44] have been identified as rare causes of isolated susceptibility to recurrent, life-threatening encephalitis caused by herpes simplex virus-1 (HSV-1) in otherwise healthy children displaying normal resistance to other forms of HSV disease and indeed to other viruses. Herpes simplex encephalitis (HSE) has been linked to defects in the release of type I IFN, and importantly, blocking TLR3-dependent production of interferons in vitro enhanced viral replication leading to cell death, effects that were abrogated by recombinant IFN- $\beta$ [41]. 
Table 6.1 Monogenic and polygenic defects in pattern recognition receptors and susceptibility to infectious diseases

\begin{tabular}{|c|c|c|c|}
\hline PRR deficiency & Presumed defect(s) & Reported infection(s) & Frequency \\
\hline \multicolumn{4}{|l|}{ TLR signaling } \\
\hline \multirow[t]{2}{*}{ MyD88 } & TLR signaling & \multirow[t]{2}{*}{ Pyogenic bacteria } & \multirow[t]{2}{*}{ Very rare } \\
\hline & (Except TLR3) & & \\
\hline \multirow[t]{2}{*}{ IRAK4 } & TLR signaling & \multirow[t]{2}{*}{ Pyogenic bacteria } & \multirow[t]{2}{*}{ Very rare } \\
\hline & (Except TLR3) & & \\
\hline NEMO & TLR signaling & Pyogenic bacteria & Very rare \\
\hline IKBA & TLR signaling & Pyogenic bacteria & Very rare \\
\hline \multirow[t]{2}{*}{ TLR3 } & dsRNA recognition & HSV & Very rare \\
\hline & dsRNA recognition & Aspergillus & Common \\
\hline UNC93B1 & dsRNA recognition & HSV & Very rare \\
\hline TRIF & TLR3 signaling & HSV & Very rare \\
\hline TRAF3 & TLR3 signaling & HSV & Very rare \\
\hline TBK1 & TLR3 signaling & HSV & Very rare \\
\hline IRF3 & TLR3 signaling & HSV & Very rare \\
\hline IRF7 & TLR7 and/or RIG-I signaling & Influenza virus & Very rare \\
\hline TLR1 & Lipopeptide recognition & Gram (+) bacteria, Candida & Common \\
\hline TLR4 & LPS recognition & Gram (-) bacteria, Aspergillus & Common \\
\hline TLR5 & Flagellin recognition & Legionella & Common \\
\hline TIRAP & TLR2 and TLR4 signaling & Mycobacterium, gram (-) bacteria & Common \\
\hline \multicolumn{4}{|l|}{ CLR signaling } \\
\hline Dectin-1 & $\beta$-Glucan recognition & Candida, Trichophyton, Aspergillus & Common \\
\hline CARD9 & CLR signaling & Trichophyton, Exophiala & Very rare \\
\hline MCL & MCF recognition & Mycobacterium & Common \\
\hline \multicolumn{4}{|l|}{ Soluble PRRs } \\
\hline MBL & Opsonization & Neisseria, Streptococcus & Common \\
\hline PTX3 & Opsonization and fungicidal activity & Aspergillus & Common \\
\hline PLG & Opsonization & Aspergillus & Common \\
\hline
\end{tabular}

PRR pattern recognition receptor, TLR Toll-like receptor, CLR C-type lectin receptor, MyD 88 myeloid differentiation primary response $88, I R A K 4$ interleukin-1 receptor (IL-1R)-associated kinase 4, NEMO nuclear factor- $\kappa \mathrm{B}(\mathrm{NF}-\kappa \mathrm{B})$

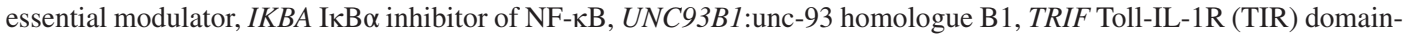
containing adapter-inducing interferon $\beta$ (IFN $\beta$ ), TRAF3 tumor necrosis factor receptor-associated factor 3, TBK1 TRAF family member-associated NF- $\kappa \mathrm{B}$ activator-binding kinase $1, I R F$ IFN regulatory factor, TIRAP TIR domaincontaining adaptor protein, $C A R D 9$ caspase recruitment domain-containing protein 9, $M C L$ macrophage C-type lectin, $M B L$ mannose-binding lectin, $P T X 3$ long pentraxin 3, $P L G$ plasminogen, $d s R N A$ double-stranded RNA, RIG-I retinoic acid-inducible gene I protein, $M C F$ mycobacterial cord factor, $H S V$ herpes simplex virus

Accordingly, children with HSE have been found to carry different heterozygous mutations in TRAF family member-associated NF- $\kappa \mathrm{B}$ activator (TANK)-binding kinase 1 (TBK1), a kinase at the crossroads of multiple IFN-inducing signaling pathways [45]. Similar to TLR3 deficiency, fibroblasts from these patients displayed enhanced viral replication, whereas responses to TLR3-independent viruses were instead preserved. These findings were substantiated by the identification of a deficiency in the signal transducer and activator of transcription 1 (STAT1) protein, a signaling molecule in the type I IFN pathway, that resulted in the production of insufficient levels of type I IFN and susceptibility to HSE [46, 47].

A novel genetic etiology of HSE due to heterozygous loss-of-function in the IFN regulatory factor 3 (IRF3) gene - activated by several TLRs that bind viruses [48] - was also identified, providing the first description of a defect in an IFNregulating transcription factor that confers increased susceptibility to viral infection of the human central nervous system [49]. Genetic susceptibility to other viruses, particularly influenza, among otherwise healthy children was also 
reported to result from compound heterozygous null mutations in IRF7 [50]. In response to influenza virus, cells from these patients produced very little type I and III IFN while failing to control viral replication, suggesting that IRF7dependent amplification of type I and III IFN is essentially required for protection against primary infection by influenza virus in humans.

Although the complete deficiencies in the TLR pathways have a large effect size, they are generally rare events (with the remarkable exception of TLR5 deficiency, discussed below) on the scale of an entire population. The genes encoding TLRs are however prominently polymorphic and encode many variant amino acid sites. Before the advent of genome-wide association studies (GWAS), polymorphisms in TLRs were considered outstanding, biologically plausible candidates for involvement in enhanced susceptibility to multiple infectious diseases [28]. Common polymorphisms in all TLRs have been described and a wealth of studies have reported their association with infection susceptibility. Excellent literature has already described those association studies in detail; therefore, we will focus mainly on discussing the most relevant studies evaluating TLR polymorphisms and their functional implications in the immunodeficient host.

As mentioned above, a TLR4 haplotype consisting of the D299G and T399I substitutions has been shown to be associated with an increased risk of sepsis [30] and is suggested to result in defective responses to lipopolysaccharide [29]. However, several other studies have failed to replicate these data at both genetic and functional levels [51], raising issues related to small sample sizes, population stratification, or the definition of case status. Interestingly, an enhanced production of TNF upon TLR4 stimulation has been demonstrated in cells from D299G, but not haplotype, carriers [52]. Nonetheless, the TLR4 haplotype was associated with the occurrence of infectious complications in HIV-1-infected patients - especially those with a history of low nadir CD4 cell counts [53] - and both sepsis and pneumonia in patients with acute myeloid leukemia following induction chemotherapy [54]. In addition, the presence of these TLR4 variants in donors of stem cell transplantation has been disclosed as an important risk factor for developing invasive aspergillosis (IA) in the corresponding patients [55], a finding that was confirmed in two independent populations $[56,57]$. Despite that the fungal ligand (or the host-derived molecule released in response to fungal infection) for TLR4 remains debated, the TLR4 haplotype was reported to underlie a delayed $\mathrm{T}$ cell and natural killer $\mathrm{T}$ cell immune reconstitution among stem cell transplant recipients [57]. The biological implications of these studies are further supported by the previous links of TLR4 variants with chronic aspergillosis in immunocompetent individuals [58] and fungal colonization in stem cell transplant recipients [59].

It is noteworthy that, in addition to TLR4, common genetic variation in other TLRs has also been proposed to influence the risk of infectious diseases. For example, genetic variation in TLR1 has been found to increase susceptibility to organ dysfunction and Gram-positive sepsis [60] and candidemia [61] and, most importantly, to impact the inflammatory response to bacterial lipopeptides [62]. On the other hand, a regulatory variant decreasing the expression of TLR3 was found to impair the recognition of fungal nucleic acids by dendritic cells and to compromise the efficient priming of protective memory $\mathrm{CD} 8+\mathrm{T}$ cell responses, thereby rendering stem cell transplant recipients more prone to develop IA [63]. Ultimately, the evaluation of regulatory variation impacting adaptive immunity might help to enhance the discriminatory potential of recent immunodiagnostic strategies based on the evaluation of fungal-specific adaptive immune responses [64]. Specifically, patients suffering from IA display an enhanced in vitro expansion of IL-10producing $\mathrm{T}$ cells following antigenic stimulation, and this has been proposed as a potential diagnostic approach in hematological patients [64]. However, we recently found that a regulatory variant in IL-10, and that underlies an increased risk of IA, regulated the expression of IL-10 and coordinated the activation of proinflammatory responses to the fungus [65]. This observation implies therefore that diagnostic 
(and immunotherapeutic) approaches are required to consider interindividual variability in immune function.

Other significant examples of variants affecting TLR signaling and associated with enhanced susceptibility to infectious disease are those in the adaptor Mal (encoded by TIRAP), which is part of the TLR2- and TLR4-dependent pathways [6]. Polymorphisms in TIRAP, particularly the S180L substitution, were initially shown to confer resistance to tuberculosis [66, 67] and septic shock [68], although a large meta-analysis failed to confirm this [69], ultimately reflecting the difficulties faced in ascribing host genetics to enhanced susceptibility to tuberculosis [13]. A similar case is also illustrated by the TLR5 deficiency. TLR5 is a receptor for flagellin, the PAMP present in the flagellum of flagellated bacteria [70]. Hawn and colleagues described a common polymorphism in TLR5 leading to the introduction of an early stop codon that was described to abrogate recognition of flagellin and leading to increased susceptibility to Legionella pneumonia [71]. Of note, this susceptibility phenotype is generally mild and affects the control of only certain flagellated pathogens. More recently, TLR5 deficiency was associated with increased risk of IA following stem cell transplantation [72], but further studies are warranted to identify the mechanism(s) by which TLR5 might influence susceptibility to fungal disease. In any case, the high and variable frequencies of this polymorphism, without forcing a severe primary immunodeficiency phenotype, suggest that it has a redundant role in host defense [73].

\section{Genetic Variation in C-Type Lectin Receptor Signaling}

In addition to TLRs, genetic variation in CLRs has been implicated in susceptibility to infectious diseases, namely, those caused by fungi (Fig. 6.2). Dectin- 1 is the major PRR for $\beta$-1,3-glucan in the fungal cell wall [20], and it also recognizes components of Mycobacterium tuberculosis [74]. Genetic analysis of a family with recurrent vulvovaginal candidiasis and onychomycosis resulted in the identification of an early stop codon in CLEC7A, the gene encoding dectin-1 [75]. The truncated protein compromised the surface expression of dectin-1 in myeloid cells, thereby affecting their ability to bind $\beta$-glucan. This defect impaired the production of cytokines namely, IL-6, TNF, and especially IL-17 - while it did not affect the ability of neutrophils to ingest and kill Candida albicans yeasts. This indicates that the contribution of dectin-1 deficiency to mucosal candidiasis likely relies on a defect in the activation of Th17-mediated immunity and not on activation of dectin-1 expressed on neutrophils.

The clinical phenotype of patients with dectin-1 deficiency is relatively mild and less severe than that of patients with classic chronic mucocutaneous candidiasis [76]. In fact, about 6 to $8 \%$ of Europeans are heterozygous for a disabling variant of the gene, and they do not, however, have an apparent immunodeficiency [75]. Yet, heterozygous carriers of the dectin-1 stop codon are more prone to develop IA $[77,78]$ and to be colonized with $C$. albicans [79] when undergoing stem cell transplantation. The fact that dectin-1 deficiency in both transplant donors and recipients synergizes toward risk of infection highlights the pivotal contribution of dectin-1 expression in multiple cell types to antifungal immunity. Thus, dectin-1 deficiency resembles a genetic polymorphism, which under specific circumstances (e.g., immunosuppression typical of certain clinical settings) is associated with susceptibility to fungal infection and/or colonization. Of note, a common polymorphism in another CLR, namely, MCL (encoded by CLECSF 8), was recently associated with susceptibility to pulmonary tuberculosis, and a non-redundant role for this receptor in anti-mycobacterial immunity was proposed [80].

Several members of a family with mutations in caspase recruitment domain-containing protein 9 (CARD9), the adaptor molecule that mediates signaling induced by dectin- 1 and other CLRs, have been found to display increased susceptibility to mucocutaneous fungal infections [81]. More recently, CARD9 deficiency was identified in patients suffering from deep dermatophytosis, a severe fungal infection caused by dermatophytes 
and characterized by extensive dermal and subcutaneous tissue invasion and by frequent dissemination to the lymph nodes and, occasionally, the central nervous system. Similar to dectin-1, patients with CARD9 mutations display a severe defect of IL-17 production [81, 82], a finding further supporting the pivotal role of the $\beta$-glucan recognition and Th17-mediated responses in antifungal immunity. Of note, individuals with inherited defects in B cell CLL/lymphoma 10 (BCL10), a protein that binds CARD9 to activate NF- $\kappa \mathrm{B}$ signaling, displayed normal responses to a variety of PAMPs but impaired NF- $\kappa \mathrm{B}$-mediated functions [83]. The fact that susceptibility to infectious diseases was not reported highlights the selective role of dectin-1-/CARD9-dependent signaling in the immune response to fungal infection. Because multiple CLRs signal through CARD9, one can hypothesize that the more severe phenotypes of CARD9 deficiency are most likely due to antifungal immunity mechanisms that are independent of dectin-1 [84-86].

\section{Defects of Soluble Pattern Recognition Receptors}

Some components of the complement system have the capacity to interact with and bind to microbial polysaccharides without transducing intracellular signals, thereby functioning as soluble PRRs. One such molecule is the circulating mannose-binding lectin (MBL), which binds carbohydrate structures of microorganisms and activates the complement system [87]. MBL deficiency was initially reported in children with recurrent bacterial infections (especially Neisseria meningitidis), in addition to viral and fungal infections [88]. Subsequent studies showed however that polymorphisms in MBL drive a strong decrease in the levels of functional protein in as much as $8 \%$ of individuals in a given population, and yet, these do not display any obvious clinical consequences [89]. There is however evidence that MBL deficiency, although not being an outright immunodeficiency, acts as a risk factor for infection, especially in conditions of immunosuppression. For example, genetically determined low serum concentrations of MBL were detected among immunocompromised patients suffering from IA [90], although the causal nature for this association remains unknown.

Another important molecule with opsonic activity is the long pentraxin 3 (PTX3), which has been shown to bind microbial moieties from a vast range of pathogens, including bacteria, viruses, and fungi [87]. Although no classic immunodeficiency phenotype related to PTX3 has been disclosed to date, common polymorphisms have been proposed as risk factors for multiple infectious diseases, most remarkably, urinary tract infections [91] and IA following stem cell transplantation [92]. The results from the latter study were confirmed by the validation of the association in a large, independent study [93]. The PTX3 deficiency was found to compromise the alveolar availability of the protein and, at a cellular level, its expression during the developmental programming of neutrophil precursors in the bone marrow, leading to defective antifungal effector mechanisms of mature cells [92]. Importantly, this association was recently replicated in recipients of lung transplant [94], highlighting a potential applicability of these markers in predicting fungal infection across patients with intrinsically different predisposing conditions. Alveolar levels of PTX3 have been demonstrated to discriminate microbiologically confirmed pneumonia in mechanically ventilated patients [95]. Given that these vary individually according to PTX3 genotypes [92], we can envisage the quantification of PTX3 in bronchoalveolar lavage fluids as a complementary surveillance measure in addition to the currently available diagnostic approaches. Finally, the fact that exogenous administration of PTX3 is able to revert the genetic defect in vitro, namely, by restoring the ability of neutrophils to adequately ingest and kill the fungus [92], further highlights the potential of PTX3-based immunotherapies to treat (or prevent) fungal infection [96].

Other relevant examples of genetic defects in soluble PRRs include the identification of a deleterious variant in plasminogen - a regulatory 
molecule with opsonic properties - as an important modulator of susceptibility to IA in humans using the genetic mapping analysis of survival data of animals subjected to experimental infection as discovery strategy [97]. Finally, microbial polysaccharides are also recognized by $\beta_{2}$-integrins such as complement receptor 3 (CD11b-CD18), which is required for neutrophil adhesion to endothelial cells and functions as a neutrophil $\beta$-glucan receptor [98]. The increased susceptibility to recurrent bacterial infections displayed by patients with leukocyte adhesion deficiency I is mainly due to defective processes of leukocyte adhesion.

\section{Opportunities for Clinical Translation of Infectious Disease Genetics}

Recent studies have clearly implicated genetic variation in PRRs and downstream signaling pathways in the susceptibility to infectious diseases. This is particularly true for several immunodeficiency syndromes, in which causal effects have been clearly defined and measures for patient-tailored management are now in place or under evaluation. Nevertheless, considerable further work is required in many cases to identify the causative alleles, their functional consequences, and the biological mechanisms by which they influence disease pathogenesis. A major challenge is to develop strategies for translating insights from the genetic basis of common infectious disease into improved patient outcomes. This objective has been hampered thus far by the size of the genotypic effect, which is often not sufficiently discriminatory to inform clinical decision-making. To enhance the predictive value of the genotypic information, future studies are expected to integrate it with other host and pathogen factors into combined predictive models to prospectively evaluate risk of and progression of disease, including treatment responses and durations, and adverse events.

It is plausible that the considerable genetic variation in PRR signaling may influence therapeutic strategies aimed at manipulating these pathways. Clinical trials that fail to take into account human genetic variation may omit relevant consequences on subgroups of individuals, such as those with extremes of inflammatory signaling. Indeed, such effects may partly account for the disappointing outcomes of clinical trials of anti-inflammatory agents for the treatment of sepsis. Thus, there is a need to identify the functional genetic variants controlling interindividual variation in PRR signaling and to stratify clinical trials of immunomodulatory agents by host genotypes.

The use of genetic information to predict risk of common infectious disease is unlikely to alter clinical practice in the near future, and the prognostic significance of genetic tools for risk assessment remains poor, even in more extensively studied, noninfectious disease traits. Clinical translation is more likely to result from the characterization of the molecular and cellular pathways involved in disease and the identification of novel targets for immunomodulatory drugs or vaccines, especially in the context of monogenic defects. Another interesting example regards the identification of the gene defect in PTX3 underlying IA, which raises the possibility to use recombinant PTX3 treatment to supplement antifungal agents, as demonstrated in animal models of infection [99, 100]. Furthermore, the application of systems biology to integrate genome-wide studies, including genomic, transcriptomic, proteomic, or metabolomic profiles, and their integration with clinical data may be a particularly powerful approach for identifying novel therapeutic targets [101]. Indeed, next-generation sequencing technologies now provide exciting avenues to pin down essential steps in host-pathogen interactions at a level of complexity previously unanticipated. Several GWAS exploring susceptibility to infection have been completed and provide unbiased insights into the genetic defects contributing to the development of disease. In this regard, recent functional genomics analyses have allowed the identification of new important players controlling susceptibility to candidemia in critical ill patients [102, 103]. These efforts are however centered on the fairly "static" role of the genetic variants. Physiological responses to infection 
require the coordinated regulation of gene expression, which may vary markedly between individuals and influence phenotypes such as protein levels, the immune cell morphology and function, and ultimately immunity to infection. Thus, genetic analysis of molecular traits such as the gene expression represents a powerful approach enabling insights into the human genomic landscape by generating expression maps useful for the functional interpretation of noncoding variants likely to arise from the ongoing genomewide initiatives [104].

\section{Conclusions and Perspectives}

The clinical features of defects in PRRs are generally credited to an impaired cytokine response underlying increased susceptibility to infections (e.g., TLR3 and MyD88 deficiencies). Although genetic defects in NLRP3 are known to lead to an overwhelming release of proinflammatory cytokines, particularly IL- $1 \beta$, these still remain to be associated with infectious diseases. Another critical point that deserves mention regards the clinical range of manifestations of PRR defects that range from severe (e.g., MyD88 and IRAK4 deficiencies) to mild (e.g., MBL, TLR5, and PTX3 deficiencies). In addition, the fact that several defects are associated with infection typically during infancy suggests that the maturation of proper adaptive immune responses may compensate for the innate immunity shortcomings. The field of primary immunodeficiencies has been shifting from research on rare familial defects in the adaptive immune system to studies of sporadic and selective disorders of the innate immunity; the defects in PRRs are an enlightening example of this change. By unraveling the functional consequences of these "experiments of nature," it has been possible to confer clinical relevance to immunologic pathways, which until now have been studied exclusively in the laboratory or using experimental models of infection.

The importance of the studies addressing polygenic susceptibility to common infectious diseases also deserves to be highlighted. Although the overall weight of the immune response is driven by adding effects of single genetic factors with modest effect sizes and their complex interactions with clinical immune dysfunctions, approaches based on individual genomics may warrant important clinical tools allowing discrimination of patients that might benefit from enhanced surveillance for infection or alternative therapies. By overcoming the limitations related to the study design discussed above, these approaches are expected to define the pathogenetic mechanisms at the basis of common infectious diseases and lay the foundations for welldesigned prospective trials ultimately endorsing genetic testing in risk stratification approaches for infection, particularly among immunocompromised hosts. Perhaps more importantly, an improved understanding of the multiple pathways directly affected by host genetic variation will contribute to innovative strategies of immunotherapy. As shown for the PTX3 deficiency in stem cell transplant recipients [92], targeting cell function (e.g., exogenous administration of lacking or deficient factors) may prove an interesting approach to be validated in the future.

Acknowledgments This work was supported by the Northern Portugal Regional Operational Programme (NORTE 2020), under the Portugal 2020 Partnership Agreement, through the European Regional Development Fund (FEDER) (NORTE-01-0145-FEDER-000013), and the Fundação para a Ciência e Tecnologia (FCT) (IF/00735/2014 to A.C. and SFRH/BPD/96176/2013 to C.C.)

\section{References}

1. Alcais A, Abel L, Casanova JL. Human genetics of infectious diseases: between proof of principle and paradigm. J Clin Invest. 2009;119(9):2506-14. https://doi.org/10.1172/JCI38111.

2. Burgner D, Jamieson SE, Blackwell JM. Genetic susceptibility to infectious diseases: big is beautiful, but will bigger be even better? Lancet Infect Dis. 2006;6(10):653-63. https://doi.org/10.1016/ S1473-3099(06)70601-6.

3. Chapman SJ, Hill AV. Human genetic susceptibility to infectious disease. Nat Rev Genet. 2012;13(3):17588. https://doi.org/10.1038/nrg3114.

4. Hill AV. Aspects of genetic susceptibility to human infectious diseases. Annu Rev Genet. 
2006;40:469-86. https://doi.org/10.1146/annurev. genet.40.110405.090546.

5. Netea MG, van der Meer JW. Immunodeficiency and genetic defects of pattern-recognition receptors. N Engl J Med. 2011;364(1):60-70. https://doi. org/10.1056/NEJMra1001976.

6. Netea MG, Wijmenga C, O'Neill LA. Genetic variation in Toll-like receptors and disease susceptibility. Nat Immunol. 2012;13(6):535-42. https://doi. org/10.1038/ni.2284.

7. van der Eijk EA, van de Vosse E, Vandenbroucke JP, van Dissel JT. Heredity versus environment in tuberculosis in twins: the 1950s United Kingdom Prophit Survey Simonds and Comstock revisited. Am J Respir Crit Care Med. 2007;176(12):1281-8. https://doi.org/10.1164/rccm.200703-435OC.

8. Sorensen TI, Nielsen GG, Andersen PK, Teasdale TW. Genetic and environmental influences on premature death in adult adoptees. $\mathrm{N}$ Engl $\mathrm{J}$ Med. 1988;318(12):727-32. https://doi.org/10.1056/ NEJM198803243181202.

9. Gingles NA, Alexander JE, Kadioglu A, Andrew PW, Kerr A, Mitchell TJ, et al. Role of genetic resistance in invasive pneumococcal infection: identification and study of susceptibility and resistance in inbred mouse strains. Infect Immun. 2001;69(1):426-34. https://doi.org/10.1128/IAI.69.1.426-434.2001.

10. Allison AC. Protection afforded by sickle-cell trait against subtertian malarial infection. Br Med J. 1954;1(4857):290-4.

11. Casanova JL, Abel L. Primary immunodeficiencies: a field in its infancy. Science. 2007;317(5838):6179. https://doi.org/10.1126/science. 1142963.

12. Misch EA, Berrington WR, Vary JC Jr, Hawn TR. Leprosy and the human genome. Microbiol Mol Biol Rev: MMBR. 2010;74(4):589-620. https://doi. org/10.1128/MMBR.00025-10.

13. Stein CM. Genetic epidemiology of tuberculosis susceptibility: impact of study design. PLoS Pathog. 2011;7(1):e1001189. https://doi.org/10.1371/journal.ppat. 1001189 .

14. O'Neill LA, Bowie AG. The family of five: TIRdomain-containing adaptors in toll-like receptor signalling. Nat Rev Immunol. 2007;7(5):353-64. https://doi.org/10.1038/nri2079.

15. Akira S, Uematsu S, Takeuchi O. Pathogen recognition and innate immunity. Cell. 2006;124(4):783801. https://doi.org/10.1016/j.cell.2006.02.015.

16. Iwasaki A, Medzhitov R. Regulation of adaptive immunity by the innate immune system. Science. 2010;327(5963):291-5. https://doi.org/10.1126/ science. 1183021.

17. Lemaitre B, Nicolas E, Michaut L, Reichhart JM, Hoffmann JA. The dorsoventral regulatory gene cassette spatzle/Toll/cactus controls the potent antifungal response in Drosophila adults. Cell. 1996;86(6):973-83.

18. Rock FL, Hardiman G, Timans JC, Kastelein RA, Bazan JF. A family of human receptors structurally related to Drosophila Toll. Proc Natl Acad Sci U S A. 1998;95(2):588-93.

19. Akira S, Takeda K. Toll-like receptor signalling. Nat Rev Immunol. 2004;4(7):499-511. https://doi. org/10.1038/nri1391.

20. Hardison SE, Brown GD. C-type lectin receptors orchestrate antifungal immunity. Nat Immunol. 2012;13(9):817-22. https://doi.org/10.1038/ ni. 2369 .

21. Geijtenbeek TB, Gringhuis SI. Signalling through C-type lectin receptors: shaping immune responses. Nat Rev Immunol. 2009;9(7):465-79.

22. Guo H, Callaway JB, Ting JP. Inflammasomes: mechanism of action, role in disease, and therapeutics. Nat Med. 2015;21(7):677-87. https://doi. org/10.1038/nm.3893.

23. Girardin SE, Boneca IG, Carneiro LA, Antignac A, Jehanno M, Viala J, et al. Nod1 detects a unique muropeptide from gram-negative bacterial peptidoglycan. Science. 2003;300(5625):1584-7. https:// doi.org/10.1126/science.1084677.

24. Girardin SE, Boneca IG, Viala J, Chamaillard M, Labigne A, Thomas G, et al. Nod2 is a general sensor of peptidoglycan through muramyl dipeptide (MDP) detection. J Biol Chem. 2003;278(11):886972. https://doi.org/10.1074/jbc.C200651200.

25. Kell AM, Gale M Jr. RIG-I in RNA virus recognition. Virology. 2015;479-480:110-21. https://doi. org/10.1016/j.virol.2015.02.017.

26. Ferwerda G, Girardin SE, Kullberg BJ, Le Bourhis L, de Jong DJ, Langenberg DM, et al. NOD2 and toll-like receptors are nonredundant recognition systems of Mycobacterium tuberculosis. PLoS Pathog. 2005;1(3):279-85. https://doi.org/10.1371/journal. ppat.0010034.

27. Netea MG, Joosten LA, van der Meer JW, Kullberg BJ, van de Veerdonk FL. Immune defence against Candida fungal infections. Nat Rev Immunol. 2015;15(10):630-42. https://doi.org/10.1038/ nri3897.

28. Schroder NW, Schumann RR. Single nucleotide polymorphisms of Toll-like receptors and susceptibility to infectious disease. Lancet Infect Dis. 2005;5(3):156-64. https://doi.org/10.1016/ S1473-3099(05)01308-3.

29. Arbour NC, Lorenz E, Schutte BC, Zabner J, Kline JN, Jones M, et al. TLR4 mutations are associated with endotoxin hyporesponsiveness in humans. Nat Genet. 2000;25(2):187-91. https://doi. org/10.1038/76048.

30. Lorenz E, Mira JP, Frees KL, Schwartz DA. Relevance of mutations in the TLR4 receptor in patients with gram-negative septic shock. Arch Intern Med. 2002;162(9):1028-32.

31. Adachi O, Kawai T, Takeda K, Matsumoto M, Tsutsui H, Sakagami M, et al. Targeted disruption of the MyD88 gene results in loss of IL-1- and IL-18mediated function. Immunity. 1998;9(1):143-50.

32. Picard C, Puel A, Bonnet M, Ku CL, Bustamante $\mathrm{J}$, Yang $\mathrm{K}$, et al. Pyogenic bacterial infections 
in humans with IRAK-4 deficiency. Science. 2003;299(5615):2076-9. https://doi.org/10.1126/ science. 1081902 .

33. von Bernuth H, Picard C, Jin Z, Pankla R, Xiao $\mathrm{H}, \mathrm{Ku} \mathrm{CL}$, et al. Pyogenic bacterial infections in humans with MyD88 deficiency. Science. 2008;321(5889):691-6. https://doi.org/10.1126/ science. 1158298.

34. Lin SC, Lo YC, Wu H. Helical assembly in the MyD88-IRAK4-IRAK2 complex in TLR/IL-1R signalling. Nature. 2010;465(7300):885-90. https://doi. org/10.1038/nature09121.

35. Bousfiha A, Picard C, Boisson-Dupuis S, Zhang SY, Bustamante J, Puel A, et al. Primary immunodeficiencies of protective immunity to primary infections. Clin Immunol. 2010;135(2):204-9. https:// doi.org/10.1016/j.clim.2010.02.001.

36. Ku CL, von Bernuth H, Picard C, Zhang SY, Chang $\mathrm{HH}$, Yang K, et al. Selective predisposition to bacterial infections in IRAK-4-deficient children: IRAK-4-dependent TLRs are otherwise redundant in protective immunity. J Exp Med. 2007;204(10):240722. https://doi.org/10.1084/jem.20070628.

37. Courtois G, Smahi A, Reichenbach J, Doffinger $\mathrm{R}$, Cancrini C, Bonnet M, et al. A hypermorphic IkappaBalpha mutation is associated with autosomal dominant anhidrotic ectodermal dysplasia and $\mathrm{T}$ cell immunodeficiency. J Clin Invest. 2003;112(7):110815. https://doi.org/10.1172/JCI18714.

38. Doffinger R, Smahi A, Bessia C, Geissmann F, Feinberg J, Durandy A, et al. X-linked anhidrotic ectodermal dysplasia with immunodeficiency is caused by impaired NF-kappaB signaling. Nat Genet. 2001;27(3):277-85. https://doi.org/10.1038/85837.

39. Janssen R, van Wengen A, Hoeve MA, ten Dam $\mathrm{M}$, van der Burg $\mathrm{M}$, van Dongen $\mathrm{J}$, et al. The same IkappaBalpha mutation in two related individuals leads to completely different clinical syndromes. J Exp Med. 2004;200(5):559-68. https://doi. org/10.1084/jem.20040773.

40. Zonana J, Elder ME, Schneider LC, Orlow SJ, Moss C, Golabi M, et al. A novel X-linked disorder of immune deficiency and hypohidrotic ectodermal dysplasia is allelic to incontinentia pigmenti and due to mutations in IKK-gamma (NEMO). Am J Hum Genet. 2000;67(6):1555-62. https://doi. org/10.1086/316914.

41. Zhang SY, Jouanguy E, Ugolini S, Smahi A, Elain G, Romero P, et al. TLR3 deficiency in patients with herpes simplex encephalitis. Science. 2007;317(5844):1522-7. https://doi.org/10.1126/ science. 1139522 .

42. Casrouge A, Zhang SY, Eidenschenk C, Jouanguy E, Puel A, Yang K, et al. Herpes simplex virus encephalitis in human UNC-93B deficiency. Science. 2006;314(5797):308-12. https://doi.org/10.1126/ science. 1128346.

43. Sancho-Shimizu V, Perez de Diego R, Lorenzo L, Halwani R, Alangari A, Israelsson E, et al. Herpes simplex encephalitis in children with auto- somal recessive and dominant TRIF deficiency. J Clin Invest. 2011;121(12):4889-902. https://doi. org/10.1172/JCI59259.

44. Perez de Diego R, Sancho-Shimizu V, Lorenzo L, Puel A, Plancoulaine S, Picard C, et al. Human TRAF3 adaptor molecule deficiency leads to impaired Toll-like receptor 3 response and susceptibility to herpes simplex encephalitis. Immunity. 2010;33(3):400-11. https://doi.org/10.1016/j. immuni.2010.08.014.

45. Herman M, Ciancanelli M, Ou YH, Lorenzo L, Klaudel-Dreszler M, Pauwels E, et al. Heterozygous TBK1 mutations impair TLR3 immunity and underlie herpes simplex encephalitis of childhood. J Exp Med. 2012;209(9):1567-82. https://doi.org/10.1084/ jem.20111316.

46. Chapgier A, Kong XF, Boisson-Dupuis S, Jouanguy E, Averbuch D, Feinberg J, et al. A partial form of recessive STAT1 deficiency in humans. J Clin Invest. 2009;119(6):1502-14. https://doi.org/10.1172/ JCI37083.

47. Dupuis S, Jouanguy E, Al-Hajjar S, Fieschi C, Al-Mohsen IZ, Al-Jumaah S, et al. Impaired response to interferon-alpha/beta and lethal viral disease in human STAT1 deficiency. Nat Genet. 2003;33(3):388-91. https://doi.org/10.1038/ng1097.

48. Gonzalez-Navajas JM, Lee J, David M, Raz E. Immunomodulatory functions of type I interferons. Nat Rev Immunol. 2012;12(2):125-35. https:// doi.org/10.1038/nri3133.

49. Andersen LL, Mork N, Reinert LS, Kofod-Olsen E, Narita R, Jorgensen SE, et al. Functional IRF3 deficiency in a patient with herpes simplex encephalitis. J Exp Med. 2015;212(9):1371-9. https://doi. org/10.1084/jem.20142274.

50. Ciancanelli MJ, Huang SX, Luthra P, Garner H, Itan Y, Volpi S, et al. Infectious disease. Lifethreatening influenza and impaired interferon amplification in human IRF7 deficiency. Science. 2015;348(6233):448-53. https://doi.org/10.1126/ science.aaa 1578 .

51. Ferwerda B, McCall MB, Verheijen K, Kullberg BJ, van der Ven AJ, Van der Meer JW, et al. Functional consequences of toll-like receptor 4 polymorphisms. Mol Med. 2008;14(5-6):346-52. https://doi. org/10.2119/2007-00135.Ferwerda.

52. Ferwerda B, McCall MB, Alonso S, GiamarellosBourboulis EJ, Mouktaroudi M, Izagirre N, et al. TLR4 polymorphisms, infectious diseases, and evolutionary pressure during migration of modern humans. Proc Natl Acad Sci U S A. 2007;104(42):16645-50. https://doi.org/10.1073/ pnas.0704828104.

53. Papadopoulos AI, Ferwerda B, Antoniadou A, Sakka V, Galani L, Kavatha D, et al. Association of tolllike receptor 4 Asp299Gly and Thr399Ile polymorphisms with increased infection risk in patients with advanced HIV-1 infection. Clin Infect Dis. 2010;51(2):242-7. https://doi.org/10.1086/653607. 
54. Schnetzke U, Spies-Weisshart B, Yomade O, Fischer M, Rachow T, Schrenk K, et al. Polymorphisms of toll-like receptors (TLR2 and TLR4) are associated with the risk of infectious complications in acute myeloid leukemia. Genes Immun. 2015;16(1):83-8. https://doi.org/10.1038/ gene.2014.67.

55. Bochud PY, Chien JW, Marr KA, Leisenring WM, Upton A, Janer M, et al. Toll-like receptor 4 polymorphisms and aspergillosis in stem-cell transplantation. N Engl J Med. 2008;359(17):1766-77. https://doi.org/10.1056/NEJMoa0802629.

56. de Boer MG, Jolink H, Halkes CJ, van der Heiden PL, Kremer D, Falkenburg JH, et al. Influence of polymorphisms in innate immunity genes on susceptibility to invasive aspergillosis after stem cell transplantation. PLoS One. 2011;6(4):e18403. https:// doi.org/10.1371/journal.pone.0018403.

57. Koldehoff M, Beelen DW, Elmaagacli AH. Increased susceptibility for aspergillosis and post-transplant immune deficiency in patients with gene variants of TLR4 after stem cell transplantation. Transplant Infect Dis (An Official Journal of the Transplantation Society). 2013;15(5):533-9. https://doi.org/10.1111/ tid.12115.

58. Carvalho A, Pasqualotto AC, Pitzurra L, Romani L, Denning DW, Rodrigues F. Polymorphisms in tolllike receptor genes and susceptibility to pulmonary aspergillosis. J Infect Dis. 2008;197(4):618-21. https://doi.org/10.1086/526500.

59. Carvalho A, Cunha C, Carotti A, Aloisi T, Guarrera O, Di Ianni M, et al. Polymorphisms in Toll-like receptor genes and susceptibility to infections in allogeneic stem cell transplantation. Exp Hematol. 2009;37(9):1022-9. https://doi.org/10.1016/j. exphem.2009.06.004.

60. Wurfel MM, Gordon AC, Holden TD, Radella F, Strout J, Kajikawa O, et al. Toll-like receptor 1 polymorphisms affect innate immune responses and outcomes in sepsis. Am J Respir Crit Care Med. 2008;178(7):710-20. https://doi.org/10.1164/ rccm.200803-462OC.

61. Plantinga TS, Johnson MD, Scott WK, van de Vosse E, Velez Edwards DR, Smith PB, et al. Toll-like receptor 1 polymorphisms increase susceptibility to candidemia. J Infect Dis. 2012;205(6):934-43. https://doi.org/10.1093/infdis/jir867.

62. Hawn TR, Misch EA, Dunstan SJ, Thwaites GE, Lan NT, Quy HT, et al. A common human TLR1 polymorphism regulates the innate immune response to lipopeptides. Eur J Immunol. 2007;37(8):2280-9. https://doi.org/10.1002/eji.200737034.

63. Carvalho A, De Luca A, Bozza S, Cunha C, D'Angelo C, Moretti S, et al. TLR3 essentially promotes protective class I-restricted memory CD8(+) T-cell responses to Aspergillus fumigatus in hematopoietic transplanted patients. Blood. 2012;119(4):967-77. https://doi.org/10.1182/ blood-2011-06-362582.

64. Potenza L, Vallerini D, Barozzi P, Riva G, Forghieri F, Beauvais A, et al. Characterization of specific immune responses to different Aspergillus antigens during the course of invasive Aspergillosis in hematologic patients. PLoS One. 2013;8(9):e74326. https://doi.org/10.1371/journal.pone.0074326.

65. Cunha C, Goncalves SM, Duarte-Oliveira C, Leite L, Lagrou K, Marques A, et al. IL-10 overexpression predisposes to invasive aspergillosis by suppressing antifungal immunity. J Allergy Clin Immunol. 2017;140(3):867-870.e9. https://doi.org/10.1016/j. jaci.2017.02.034.

66. Hawn TR, Dunstan SJ, Thwaites GE, Simmons CP, Thuong NT, Lan NT, et al. A polymorphism in Tollinterleukin 1 receptor domain containing adaptor protein is associated with susceptibility to meningeal tuberculosis. J Infect Dis. 2006;194(8):1127-34. https://doi.org/10.1086/507907.

67. Khor CC, Chapman SJ, Vannberg FO, Dunne A, Murphy C, Ling EY, et al. A Mal functional variant is associated with protection against invasive pneumococcal disease, bacteremia, malaria and tuberculosis. Nat Genet. 2007;39(4):523-8. https://doi. org/10.1038/ng1976.

68. Ferwerda B, Alonso S, Banahan K, McCall MB, Giamarellos-Bourboulis EJ, Ramakers BP, et al. Functional and genetic evidence that the Mal/ TIRAP allele variant $180 \mathrm{~L}$ has been selected by providing protection against septic shock. Proc Natl Acad Sci U S A. 2009;106(25):10272-7. https://doi. org/10.1073/pnas.0811273106.

69. Miao R, Li J, Sun Z, Xu F, Shen H. Meta-analysis on the association of TIRAP S180L variant and tuberculosis susceptibility. Tuberculosis. 2011;91(3):26872. https://doi.org/10.1016/j.tube.2011.01.006.

70. Hayashi F, Smith KD, Ozinsky A, Hawn TR, Yi EC, Goodlett DR, et al. The innate immune response to bacterial flagellin is mediated by Toll-like receptor 5. Nature. 2001;410(6832):1099-103. https://doi. org/10.1038/35074106.

71. Hawn TR, Verbon A, Lettinga KD, Zhao LP, Li SS, Laws RJ, et al. A common dominant TLR5 stop codon polymorphism abolishes flagellin signaling and is associated with susceptibility to legionnaires' disease. J Exp Med. 2003;198(10):1563-72. https:// doi.org/10.1084/jem.20031220.

72. Grube M, Loeffler J, Mezger M, Kruger B, Echtenacher B, Hoffmann P, et al. TLR5 stop codon polymorphism is associated with invasive aspergillosis after allogeneic stem cell transplantation. Med Mycol. 2013;51(8):818-25. https://doi.org/10.3109/ 13693786.2013.809630.

73. Wlasiuk G, Khan S, Switzer WM, Nachman MW. A history of recurrent positive selection at the toll-like receptor 5 in primates. Mol Biol Evol. 2009;26(4):937-49. https://doi.org/10.1093/molbev/ msp018.

74. Yadav M, Schorey JS. The beta-glucan receptor dectin-1 functions together with TLR2 to mediate macrophage activation by mycobacteria. Blood. 2006;108(9):3168-75. https://doi.org/10.1182/ blood-2006-05-024406. 
75. Ferwerda B, Ferwerda G, Plantinga TS, Willment JA, van Spriel AB, Venselaar $\mathrm{H}$, et al. Human dectin-1 deficiency and mucocutaneous fungal infections. N Engl J Med. 2009;361(18):1760-7. https:// doi.org/10.1056/NEJMoa0901053.

76. Puel A, Doffinger R, Natividad A, Chrabieh M, Barcenas-Morales G, Picard C, et al. Autoantibodies against IL-17A, IL-17F, and IL-22 in patients with chronic mucocutaneous candidiasis and autoimmune polyendocrine syndrome type I. J Exp Med. 2010;207(2):291-7. https://doi.org/10.1084/ jem.20091983.

77. Chai LY, de Boer MG, van der Velden WJ, Plantinga TS, van Spriel AB, Jacobs C, et al. The Y238X stop codon polymorphism in the human beta-glucan receptor dectin-1 and susceptibility to invasive aspergillosis. J Infect Dis. 2011;203(5):736-43. https://doi.org/10.1093/infdis/jiq102.

78. Cunha C, Di Ianni M, Bozza S, Giovannini G, Zagarella S, Zelante $\mathrm{T}$, et al. Dectin-1 Y238X polymorphism associates with susceptibility to invasive aspergillosis in hematopoietic transplantation through impairment of both recipient- and donor-dependent mechanisms of antifungal immunity. Blood. 2010;116(24):5394-402. https://doi. org/10.1182/blood-2010-04-279307.

79. Plantinga TS, van der Velden WJ, Ferwerda B, van Spriel AB, Adema G, Feuth T, et al. Early stop polymorphism in human DECTIN-1 is associated with increased candida colonization in hematopoietic stem cell transplant recipients. Clin Infect Dis. 2009;49(5):724-32. https://doi. org/10.1086/604714.

80. Wilson GJ, Marakalala MJ, Hoving JC, van Laarhoven A, Drummond RA, Kerscher B, et al. The C-type lectin receptor CLECSF8/CLEC4D is a key component of anti-mycobacterial immunity. Cell Host Microbe. 2015;17(2):252-9. https://doi. org/10.1016/j.chom.2015.01.004.

81. Glocker EO, Hennigs A, Nabavi M, Schaffer AA, Woellner C, Salzer U, et al. A homozygous CARD9 mutation in a family with susceptibility to fungal infections. N Engl J Med. 2009;361(18):1727-35. https://doi.org/10.1056/NEJMoa0810719.

82. Lanternier F, Pathan S, Vincent QB, Liu L, Cypowyj S, Prando C, et al. Deep dermatophytosis and inherited CARD9 deficiency. N Engl J Med. 2013;369(18):1704-14. https://doi.org/10.1056/ NEJMoa1208487.

83. Torres JM, Martinez-Barricarte R, Garcia-Gomez $\mathrm{S}$, Mazariegos MS, Itan Y, Boisson B, et al. Inherited BCL10 deficiency impairs hematopoietic and nonhematopoietic immunity. J Clin Invest. 2014;124(12):5239-48. https://doi.org/10.1172/ JCI77493.

84. Bugarcic A, Hitchens K, Beckhouse AG, Wells CA, Ashman RB, Blanchard H. Human and mouse macrophage-inducible C-type lectin (Mincle) bind
Candida albicans. Glycobiology. 2008;18(9):679_ 85. https://doi.org/10.1093/glycob/cwn046.

85. Sato K, Yang XL, Yudate T, Chung JS, Wu J, LubyPhelps K, et al. Dectin-2 is a pattern recognition receptor for fungi that couples with the Fc receptor gamma chain to induce innate immune responses. J Biol Chem. 2006;281(50):38854-66. https://doi. org/10.1074/jbc.M606542200.

86. Yamasaki S, Ishikawa E, Sakuma M, Hara H, Ogata $\mathrm{K}$, Saito T. Mincle is an ITAM-coupled activating receptor that senses damaged cells. Nat Immunol. 2008;9(10):1179-88.

https://doi.org/10.1038/ ni. 1651 .

87. Foo SS, Reading PC, Jaillon S, Mantovani A, Mahalingam S. Pentraxins and Collectins: friend or foe during pathogen invasion? Trends Microbiol. 2015;23(12):799-811. https://doi.org/10.1016/j. tim.2015.09.006.

88. Eisen DP, Minchinton RM. Impact of mannosebinding lectin on susceptibility to infectious diseases. Clin Infect Dis. 2003;37(11):1496-505. https://doi.org/10.1086/379324.

89. Sprong T, van Deuren M. Mannose-binding lectin: ancient molecule, interesting future. Clin Infect Dis. 2008;47(4):517-8. https://doi.org/10.1086/590007.

90. Lambourne J, Agranoff D, Herbrecht R, Troke PF, Buchbinder A, Willis F, et al. Association of mannose-binding lectin deficiency with acute invasive aspergillosis in immunocompromised patients. Clin Infect Dis. 2009;49(10):1486-91. https://doi. org/10.1086/644619.

91. Jaillon S, Moalli F, Ragnarsdottir B, Bonavita E, Puthia M, Riva F, et al. The humoral pattern recognition molecule PTX3 is a key component of innate immunity against urinary tract infection. Immunity. 2014;40(4):621-32. https://doi.org/10.1016/j. immuni.2014.02.015.

92. Cunha C, Aversa F, Lacerda JF, Busca A, Kurzai O, Grube M, et al. Genetic PTX3 deficiency and aspergillosis in stem-cell transplantation. N Engl J Med. 2014;370(5):421-32. https://doi.org/10.1056/ NEJMoa1211161.

93. Wojtowicz A, Lecompte TD, Bibert S, Manuel O, Rueger S, Berger C, et al. PTX3 polymorphisms and invasive mold infections after solid organ transplant. Clin Infect Dis. 2015;61(4):619-22. https://doi. org/10.1093/cid/civ386.

94. Cunha C, Monteiro AA, Oliveira-Coelho A, Kuhne J, Rodrigues F, Sasaki SD, et al. PTX3-based genetic testing for risk of aspergillosis after lung transplant. Clin Infect Dis. 2015;61(12):1893-4. https://doi. org/10.1093/cid/civ679.

95. Mauri T, Coppadoro A, Bombino M, Bellani G, Zambelli V, Fornari C, et al. Alveolar pentraxin 3 as an early marker of microbiologically confirmed pneumonia: a threshold-finding prospective observational study. Crit Care. 2014;18(5):562. https://doi. org/10.1186/s13054-014-0562-5. 
96. Carvalho A, Cunha C, Bistoni F, Romani L. Immunotherapy of aspergillosis. Clin Microbiol Infect (The Official Publication of the European Society of Clinical Microbiology and Infectious Diseases). 2012;18(2):120-5. https://doi. org/10.1111/j.1469-0691.2011.03681.x.

97. Zaas AK, Liao G, Chien JW, Weinberg C, Shore D, Giles SS, et al. Plasminogen alleles influence susceptibility to invasive aspergillosis. PLoS Genet. 2008;4(6):e1000101. https://doi.org/10.1371/journal.pgen.1000101.

98. Notarangelo LD, Badolato R. Leukocyte trafficking in primary immunodeficiencies. J Leukoc Biol. 2009;85(3):335-43. https://doi.org/10.1189/ jlb.0808474.

99. Lo Giudice P, Campo S, De Santis R, Salvatori G. Effect of PTX3 and voriconazole combination in a rat model of invasive pulmonary aspergillosis. Antimicrob Agents Chemother. 2012;56(12):64002. https://doi.org/10.1128/AAC.01000-12.

100. Marra E, Sousa VL, Gaziano R, Pacello ML, Arseni B, Aurisicchio L, et al. Efficacy of PTX3 and posaconazole combination in a rat model of invasive pulmonary aspergillosis. Antimicrob Agents
Chemother. 2014;58(10):6284-6. https://doi. org/10.1128/AAC.03038-14.

101. Oliveira-Coelho A, Rodrigues F, Campos A Jr, Lacerda JF, Carvalho A, Cunha C. Paving the way for predictive diagnostics and personalized treatment of invasive aspergillosis. Front Microbiol. 2015;6:411. https://doi.org/10.3389/ fmicb.2015.00411.

102. Kumar V, Cheng SC, Johnson MD, Smeekens SP, Wojtowicz A, Giamarellos-Bourboulis E, et al. Immunochip SNP array identifies novel genetic variants conferring susceptibility to candidaemia. Nat Commun. 2014;5:4675. https://doi.org/10.1038/ ncomms5675.

103. Smeekens SP, Ng A, Kumar V, Johnson MD, Plantinga TS, van Diemen C, et al. Functional genomics identifies type I interferon pathway as central for host defense against Candida albicans. Nat Commun. 2013;4:1342. https://doi.org/10.1038/ ncomms 2343 .

104. Fairfax BP, Knight JC. Genetics of gene expression in immunity to infection. Curr Opin Immunol. 2014;30C:63-71. https://doi.org/10.1016/j. coi.2014.07.001. 